\title{
IPS Spotlight
}

\section{Profille: Jennie Wilson}

\section{Editor, Journal Infection Prevention; IPS} Board member

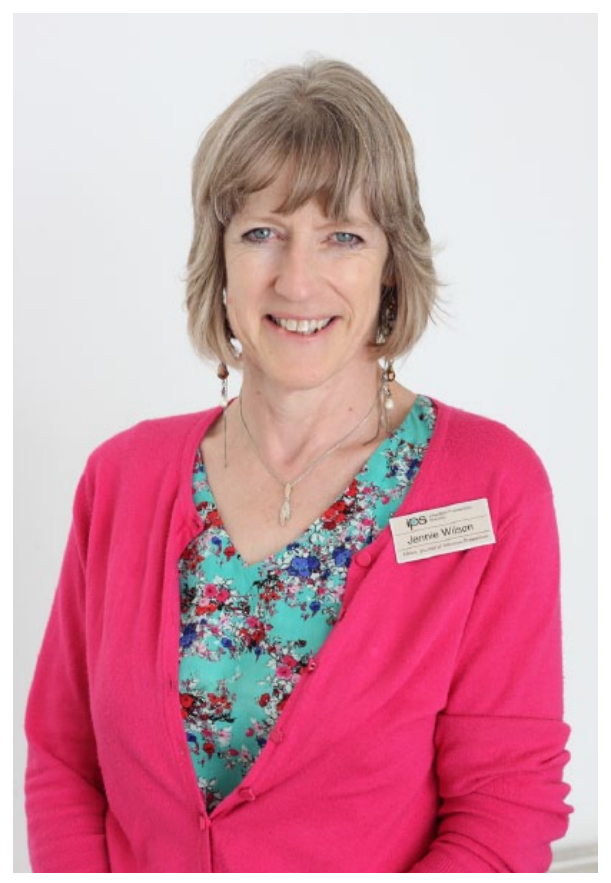

\section{It started in Liverpool}

I guess infection control was an obvious career choice for me once I completed my training in the early 1980s. I trained at the Royal Liverpool Hospital but as part of one of the first 'degree nursing' courses at Liverpool University which meant that over the 4.5 years of the course I acquired both an RGN and an honours degree in microbiology. I had not come across microbiology before but was totally fascinated by both the science and the practicalities of manipulating agar plates, test tubes and Bunsen burners in the laboratory. I was reluctant to leave Liverpool, which I loved, and where I had refined a pretty good Scouse accent so that I wasn't perceived as a 'posh southerner'. However, I moved on to a post as Research Assistant with the Nursing Practice Research Unit, then based in Northwick Park Hospital in London. The project I worked on was about the

\author{
Journal of Infection Prevention \\ 2016, Vol. 17(4) 190-193 \\ DOI: $10.1|77 /| 757|774| 6650203$ \\ (C) The Author(s) 2016 \\ Reprints and permissions: \\ sagepub.co.uk/journalsPermissions.nav \\ jip.sagepub.com
}

(S)AGE management of urine catheters and Brenda Roe (now a Professor) and myself spent many hours in hospitals around London seeking out patients with catheters, many of which the 'nurse in charge' was unaware of!

\section{The early days in infection control}

It was during this time that I came to perceive infection control as an interesting job and was lucky enough to secure a post at St George's hospital in Tooting, London. In those days, ICNs were a rarity and this was the first such post at the hospital. Fortunately, it took me over an hour to get to work on the train, giving me plenty of time to read Ayliffe's book on the way so that I could give the appearance of being an expert! Since ICNs in those days were primarily 'sole practitioners' (and there were no computers!), we relied heavily on networking with other ICNs to share information, ideas and expertise. I made many lifelong friends through the London group of the Infection Control Nurses Association (as it was then) and it was the beginning of my involvement with this great organisation.

The emergence of HIV in the 1980s began to increase the profile of infection control and more posts began to be developed to support work around HIV prevention. Then at Charing Cross Hospital, I worked closely with Robert Pratt and Heather Loveday in the School of Nursing, teaching infection control to students and developing education focused on HIV. This experience strongly influenced my first edition of Infection Control in Clinical Practice, which I rather rashly started writing in 1990 when on maternity leave and subsequently took over my life for large chunks on the next 10 years! We also introduced the concept of universal infection control precautions aimed at encouraging staff to use gloves for direct contact with all body fluids (Wilson and Breedon, 1990) - somewhat ironic given my current interest in the overuse and misuse of gloves (Loveday et al., 2014; Wilson et al., 2015).

\section{The influence of Dr Robert Haley}

In the late 1980s I heard Robert speak at the ICNA conference in Harrogate about the findings of the Study on the Efficacy of Nosocomial Infection Control (Haley et al., 
1985). Haley's evidence that surveillance and feedback of data on rates of UTI, BSI and SSI was critical to preventing HCAI, and that education and policies alone were not effective, was a very powerful, if challenging, message. In the UK at this time HCAI surveillance was rare, was primarily focused on 'alert organisms' such as MRSA, and did not involve feedback to clinicians. It was this conference session that sparked my interest in and passion for surveillance as a key component of infection control and I set about trying to establish an SSI surveillance system in my own hospital.

\section{The Health Protection Agency days}

My interest in surveillance inevitably lead to the door of the HPA, although I distinctly remember turning up on my first day as 'Programme Lead - Surveillance' thinking that I must be mad! I hated the thought of moving away from the varied and vibrant environment of a large London hospital, my role as ICN and losing contact with patients. However, I eventually got used to it. In the 17 years that I spent at the HPA I was privileged to work on, and influence, some of the major initiatives aimed at supporting surveillance and the prevention of HCAI in the UK and Europe. We had a strong relationship with the Department of Health who were keen to learn from the SENIC study and funded us to conduct two major projects: the Socio-economic Burden of HCAI (Plowman et al., 2001) and the Clinical Audit of Hospital Infection Control Activity (Glynn et al., 1997) which established the principles of HCAI surveillance in England. These projects led to the establishment of the National Nosocomial Infection Surveillance System (or 'ninnies' as we affectionately called it) where we developed systems to support and encourage hospitals in England to use surveillance as part of infection prevention and control programmes. From the early days of piloting the surveillance protocols, there was immense interest from practitioners around the country and the uptake of the (then voluntary) system was remarkable. Sadly, the political focus moved towards single organisms and only the SSI programme continued; unfortunate given that pneumonia and UTI consistently account for the majority of HCAI acquired in acute care settings! My belief in the power of data to change practice remains undented. In leading the Surgical Site Infection Surveillance Service for 10 years I saw many, many examples of how data captured through robust surveillance was instrumental in influencing clinicians, reducing rates of SSI and preventing patients acquiring infection.

\section{What now?}

So having started out dabbling in research I have returned to the academic environment as Associate Professor at the Richard Wells Research Centre at the University of West London. This institution has a strong reputation in research related to HCAI and a focus on resolving practical infection control problems. My time at RWRC has given me the opportunity take on some new challenges and indulge some different passions! In particular, completing my $\mathrm{PhD}$ in 2014, working on the Epic guidelines and establishing a new course for infection control professionals (http://www. uwl.ac.uk/course/advanced-practice-infectionprevention-and-control/34830).

I am also relishing the opportunity to work on research aimed at improving practice at a clinical level. These include a project we are running on reducing dehydration in care homes residents, which is linked to my previous work on the increased risk of $E$. coli bacteraemia in summer (Wilson et al., 2011); the OneTogether project to support the prevention of SSI (Wilson et al., 2015); as well as our work on the misuse of gloves.

\section{Contributing to the work of the Infection Prevention Society}

The ICNA, and now IPS, has been a major influence and support in my 30-year career as an infection control specialist and working for the Society is both an enjoyable and rewarding experience. I have been actively involved initially at the London Branch level, but subsequently in the education sub-committee, where I worked closely with Elizabeth Jenner to develop the first ICN competencies, and more recently as 'Board member without portfolio'. I took on the role of Editor of JIP in September 2014 and am very pleased to be working with our excellent publishers SAGE and Editorial Management Group to ensure that our journal continues to be an important vehicle for the dissemination of research and expert knowledge on infection prevention and control, both in the UK and worldwide. Although it is hard work, I get great satisfaction from seeing each copy of the journal come together and supporting authors in the process of publishing their work.

My career in infection control has been an amazing journey and it has been a privilege to meet, work with, and learn from so many incredible people in a discipline that I love.

\section{References}

Glynn A, Ward V, Wilson J, Charlett A, Cookson B, Taylor L and Cole N. (1997) Hospital-acquired infection: surveillance, policies and practice. London: Public Health Laboratory Service.

Haley RW. (1985) Surveillance by objective: a new priority-directed approach to the control of nosocomial infection. American Journal of Infection Control 12: 78-89.

Loveday HP, Lynam S, Singleton J and Wilson JA. (2014) Clinical glove use: healthcare workers' actions and perceptions Journal of Hospital Infection 86: 110-116.

Plowman R, Graves N, Griffin M, Roberts JA, Swan AV, Cookson B and Taylor L. (2001) The rate and cost of hospital-acquired infections occurring in patients admitted to selected specialties of a district general hospital in England and the national burden imposed. Journal of Hospital Infection 47: 198-209. 
Wilson J and Breedon P. (1990) Universal precautions. Nursing Times 86: $67-70$.

Wilson J, Elgohari S, Livermore D, Cookson B, Johnson A, Lamagni T, Chronias A and Sheridan E. (2011) Trends among pathogens reported as causing bacteraemia in England: 2004-08. Clinical Microbiology \& Infection 17: 451-458.

Wilson J, Prieto J, Singleton J, O'Connor V, Lynam S and Loveday H. (2015) The misuse and overuse of non-sterile gloves: application of an audit tool to define the problem. Journal of Infection Prevention 16: $24-31$.

Wilson J, Topley K, Stott D, Neachell J and Gallagher R. (2015) The OneTogether collaborative approach to reduce the risk of surgical site infection: identifying the challenges to assuring best practice. Journal of Infection Prevention 16: 99-100.

\section{Tracey Cooper \\ Deputy Editor, Journal Infection Prevention}

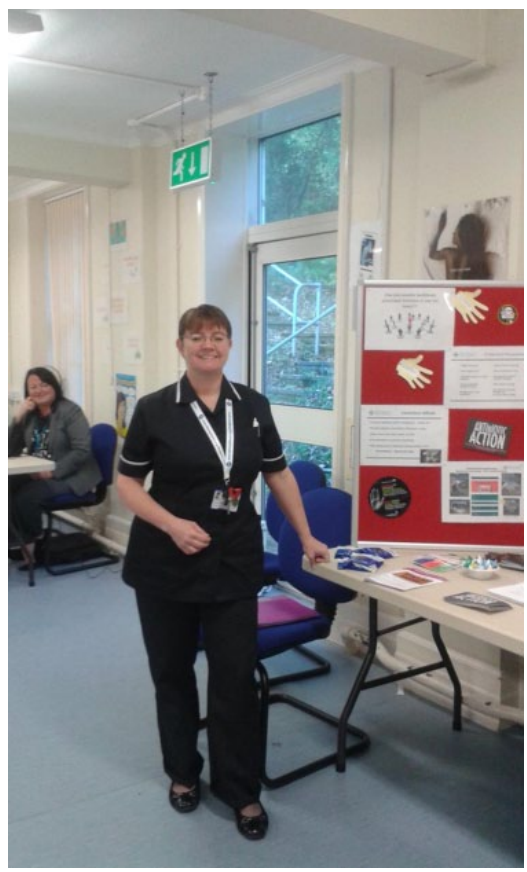

\section{How and when did you become interested in infection prevention?}

My clinical background is mostly intensive and coronary care nursing. I remember being on a night shift while working in Torbay, Devon and spotting an advert for an 18-month secondment as an Audit Project Nurse. This was a fixed-term secondment with the Public Health Laboratory Service in England. This turned out to be a really exciting project to develop a national surveillance programme in England and was the forerunner of the national Surgical Site Infection Surveillance Programme (as Jennie refers to above). I was lucky enough to make some career-long friends as part of this project, and am still in touch with several of them.
The project finished in 1996, and by that time I understood just how important it was to protect people from avoidable infection, and knew that I wanted to work in infection control (as it was then) as a career. Luckily for me, within a few months an opportunity came up to work in Exeter and I was able to get the role. I still remember my very first day, when someone described me as the new Infection Control Nurse - and thinking to myself how little I knew. Fortunately, I had fantastic support and mentorship from more experienced colleagues in Exeter and across the whole South-West Branch of the ICNA.

\section{Which roles have you held within the Society, and how have you benefited?}

I have moved around quite a bit professionally during my career and am now in my fourth different branch as a member. I started in a permanent infection prevention role in 1996, when the Society was still the Infection Control Nurses Association (ICNA). During that time, I have held quite a few roles. The South-West Branch supported me as a new practitioner in the specialty. When I moved to the Isle of Wight, I joined the Wessex Branch, eventually serving as the Co-ordinator of the Branch Conference Organising Group (in those days we all organised our branch conferences ourselves) and subsequently as the Branch Co-ordinator. I enjoyed those roles and started to learn new skills, and about the workings and responsibilities of a UK-wide charity.

When I stood down as Branch Co-coordinator, I volunteered to join the ICNA Editorial Board. Circumstances conspired and only a few months after that there was a vacancy for the Editor and no obvious person to step into the role. I enjoy a challenge, am willing to give things a try and was persuaded by one of the ICNA Board Officers to have a go. This taught me so much about publication, peer review and the challenges of having truly fixed deadlines for the publisher to be able to produce the journal. Through this role I networked with a great many members and met some fantastic practitioners who have also remained colleagues through the rest of my career.

The experience of being part of the ICNA, and subsequently the IPS Board when the Society changed in 2007, was amazing. This subsequently led to me taking up the roles of Vice President and then President. I represented the Society at a wide range of events in a number of different countries, and the opportunity to network across many societies and organisations gave me a much greater understanding of the differing roles and contributions of a variety of professions and organisations.

All of these experiences directly helped me to do my day-job, as I worked in a range of increasingly senior posts on the Isle of Wight, in Southampton and then in South London. The things I learned and the network of friends 
and colleagues I built up through my Society roles are still invaluable in my current role in North Wales.

It is wonderful to once again be supporting the work of the Society and the IPS Editor.

\section{What has been the highlight for you?}

I have been very privileged to hold the various roles within the Society, but undoubtedly the greatest honour for me was to serve the membership in the role of IPS President from 2010-2012. The President fulfils a wide variety of functions and for me some of the most fantastic experiences within that role were:

- Chairing the Board and directly helping steer the direction of the Society to ensure it meets members needs and supports them to make a difference for patients and the wider population.

- Welcoming members and the many different eminent infection prevention and control practitioners to the Society annual conference each year; and for me the first time I welcomed Professor Graham Ayliffe to our conference was particularly special, as his is a name I had known and respected all of my infection prevention career.

- Attending the International Federation of Infection Control (IFIC) conference in Venice and presenting some of the work of the Society to international delegates.

\section{What would you say to others considering taking on IIPS roles?}

I never thought I had the skills to take on a role within the Wessex Branch, but was persuaded to have a go by others. The same is true for my role as IPS Editor. What I learned from both these roles was that there are always plenty of people around the Society who will help, support and give advice if you get stuck. Yes, each role comes with some work to do, but the benefits personally and professionally are well worth the effort. There are a whole range of roles available at branch and national level within the Society - something for everyone. Just put yourself forward and have a go! 